\title{
The Impacts of a Face-to-Face Training in Combination with LINE Application and Professional Learning Communities on English Teacher Development
}

\author{
Areerug Mejang ${ }^{1} \&$ Wannaprapha Suksawas ${ }^{1}$ \\ ${ }^{1}$ School of Educational Studies, Sukhothai Thammathirat Open University, Nonthaburi, Thailand \\ Correspondence: Wannaprapha Suksawas, School of Educational Studies, 6th Floor, Academic 3 Building \\ Sukhothai Thammathirat Open University, 9/9, Chaeng Wattana Road, Bang Phoot t, Pak Kret, Nonthaburi, \\ Thailand 11120 .
}

Received: February 10, 2021

Accepted: March 12, 2021

Online Published: March 15, 2021

doi: 10.5539/elt.v14n4p25

URL: https://doi.org/10.5539/elt.v14n4p25

\begin{abstract}
This study examines the impact of a teacher-training program on the development of teachers' knowledge, skills, and attitudes towards English reading teaching. The training program was implemented in combination with the use of LINE (a message application) and the teachers' participation in school-based professional learning communities. The framework supports the training of English teachers to teach students in accordance with the national core curriculum and its emphasis on reading skills. The participants of this study were 50 English teachers working in the central part of Thailand. Four research instruments were used to collect data: a 12-item pre-test and post-test on teaching English reading skills covering the content of the training, an open-ended form for recording emerging points from the implementation of the lesson plan and preparation of the video clip, a survey including 5-point Likert-scale options and an open-ended response field to assess teachers' satisfaction with the training program, and an observation form of the teachers' level of participation in the training program. The findings of this study revealed that participants had developed in three major areas: knowledge, skills, and attitude, and they indicated satisfaction with the training program in all areas. The participants' post test scores was higher than the pre-test scores. With a statistical significance improvement $(\mathrm{p}=0.05)$. Participants demonstrated their skills in designing more creative lesson plans with suitable educational objectives. Finally, the participants reflected a positive attitude towards their participation in the PLC. The significance of this study is related to the theoretical and pedagogical implications of the knowledge, skills, and attitudes of teachers teaching English reading skills in an EFL context.
\end{abstract}

Keywords: teaching English reading, teacher training, professional learning communities

\section{Introduction}

\subsection{Rationale of the Study}

Today's modern world is considered an era of information flow and technological advancement. As such, English reading skills are crucial as a person's reading comprehension ability helps to promote continuous learning and the acquisition of knowledge through different types of learning mediums such as textbooks, books, journals, and educational search engines, and etcetera. (Abdelhalim, 2017; Mejang, 2018; Nation \& Macalister, 2021; Petchinalert \& Aksornjarung, 2017)

In Thailand, developing learners' reading skills is one of the most significant goals in English language teaching and learning at all levels. However, teaching English reading skills in the Thai context is associated with numerous challenges as evidenced in the results of the Thai Ordinary National Educational Test (O-NET) administered by the National Institute of Educational Testing Service (NIETS). National tests of Grade 9 and Grade 12 students in Thailand are held annually. Half the exam items mostly test reading comprehension skills. Unfortunately, the test results are not satisfactory. In 2019, for instance, the average score for Grade 9 students regarding their English reading comprehension was 33.25 and 29.20 out of 100 for Grade 12 students (The National Institute of Educational Testing Service Public Organization, 2020). This reflects a problem with English language teaching in Thailand's educational system that needs urgent attention from all related sectors.

Major factors hindering EFL students' success in developing their English reading comprehension ability include 
inadequate knowledge of the English language, lack of background knowledge of English structures, unfamiliar topics being read, and inadequate reading techniques (Mejang, 2004; Pustika \& Wiedarti, 2019). Moreover, the teaching and learning processes in the classroom including the learning materials used by teachers may also impact student learning performance. In particular, the teaching approaches and methods employed by teachers directly influence student learning achievement (Feeney \& Gajaseni, 2020; Mejang, 2018). Many English teachers in foreign language reading classrooms teach the students by starting with vocabulary and grammatical structures considered to be difficult for them. After that, questions related to the assigned topic are asked and discussed. The students are then asked to either read the text aloud or to engage in silent reading, and teachers sometimes explain or translate a section of text for the students. After reading, the students complete different types of exercises such as responding to multiple-choice questions, providing short-answers, and matching responses to test their reading comprehension skills (Block, 1992; Sukchotrat, 2012). This traditional way of teaching reading neither promotes critical thinking by the students nor personal control over their reading skills development because the students do not get to read freely (Bernhardt, 1991 as cited in Urquhart \& Weir, 1998). Studies on teaching English reading for EFL students revealed limited reading strategies used in the classroom and the students seem not to know the purposes of their reading (Pan, 2009; Sawangsamutchai \& Rattanavich, 2016). As a result, teachers should creatively introduce and promote English reading strategies in the classroom.

Additionally, findings related to reading skills development reported in studies of secondary school teachers' English teaching and learning management show that teachers tended to hold misconceptions about content knowledge on English reading instruction. Most teachers identified content knowledge as reading texts which are actually teaching materials (Gordon, 2015). Moreover, teachers are increasingly required to adopt the role of learning designers by being more creative in designing their classrooms (Garcia, 2014; Reinders \& Pegrum, 2017). Therefore, this study aims to contribute to promoting teachers' creativity in designing their English reading classes which are in line with the Thai national curriculum objectives in a form of training.

Creativity in language teaching is increasingly recognized for its potential to help learners to develop the higher-order thinking skills deemed important for learning in the $21^{\text {st }}$ century (Fan \& $\mathrm{Li}, 2020$ ). However, teachers of English as a Foreign Language (EFL) in Thailand widely use commercial English language books and their contents as the only teaching material or a starting point for their lessons rather than the expected learning outcomes for students as identified in the national curriculum (Ishihara \& Paller, 2017). Researchers in material development have severely criticized commercially available English language teaching materials because the materials seem to "offer students few opportunities to develop their pragmatic competence, ability to exercise appropriate use and interpretation of the language in a given sociocultural context" (Ishihara \& Paller, 2017, p. 87). The aim of this paper is not to reiterate this argument, but to direct the attention of practitioners, material developers, and teachers to the core components of teaching materials that may better align with current Second Language Acquisition theories and research. The components introduced by Darici and Tomlinson (2017, p. 72) comprise the concepts they propose to facilitate second language (L2) acquisition through the teaching materials by:

1) providing rich exposure to language in use;

2) providing texts and tasks likely to stimulate affective engagement;

3) providing texts and tasks likely to stimulate cognitive engagement;

4) providing meaningful and spaced recycling;

5) attempting to stimulate a willing investment of time and energy (e.g. motivation)

6) helping students to pay attention to form after meaning-focused activities;

7) providing students with opportunities to use English for communication; and

8) attempting to stimulate students/text interaction, student/student interaction and student/teacher interaction.

These concepts may enable teachers to create materials that provide optimal learning affordances to the learners. In addition to inadequate teaching materials, however, the research mentioned above also found that teachers had inadequate knowledge of different methods of teaching English reading. As such, the teachers' classroom activities did not effectively motivate student learning or increase student enthusiasm, and they demonstrated little variation in their approaches to student assessment and evaluation (Mejang, 2018; Spangler \& Mazzante, 2015).

Given the issues mentioned above, it is essential to improve Thai English teachers' knowledge of teaching 
English reading skills and to support them to apply their new knowledge and understanding in their teaching practices. There are various methods for upgrading the knowledge and skills of teachers such as training programs, seminars, knowledge-sharing forums, training courses abroad, and study trips to observe teaching systems of different international schools, inclusive schools, etc. (Fan \& Li, 2020). However, it is generally agreed that the most appropriate way to develop teachers' knowledge and skills is to provide them with training on a regular and systematic basis. Naofaie (2020) suggested that effective and successful teacher training must include a follow-up as this helps to stimulate teachers to improve their practices. It also allows teachers to identify and discuss the difficulties and issues they may be experiencing in applying the knowledge gained from training to their teaching practices. Such information access through follow-up sessions can then be used as a guideline for finding the right solutions, support, and assistance.

In light of this, this study established a training program entitled "Insight into EFL Reading Instruction" based on the Teacher Development project initiated by the Ministry of Education in Thailand. The training program provides teachers who are interested in developing their English reading teaching skills with the opportunity to increase their knowledge and understanding of different teaching aspects. Such aspects include content components related to teaching English reading skills, methods for developing different learning activities for application in an English reading classroom, and how to vary their approaches to assessing and evaluating student English reading skills development. The program consisted of face-to-face training and follow-up sessions, with the latter conducted both online and face-to-face. Participating in these activities enabled the teachers to acquire new knowledge from the program trainers as well as from their interactions with other teachers in the program. This also created a sustainable learning community. The training promoted teachers' creativity in incorporating activities suitable for evaluating learning objectives. In doing so, the trainers set the training objectives that cover learning domains namely Cognitive: mental skills (Knowledge), Psychomotor: manual or physical skills (Skills), and Affective: growth in feelings or emotional areas (Attitude) introduced by Bloom and associates (Bloom, 1996; Krathwohl, Bloom, \& Bertram, 1973). The domains are often referred to when one plans to design a course or a training program. This taxonomy of learning behaviors can be thought of as the expected outcomes of the training process.

\section{Method}

\subsection{Study Aims}

This study had two main aims:

1) To investigate the effect of a teacher-training program on the knowledge, skills, and attitudes of teachers; and

2) To evaluate the level of teacher satisfaction towards the training program.

\subsection{Training Program Objectives}

To begin, the researchers gathered information about the teachers' needs and requirements in relation to teaching reading. They then designed the training program to reflect the gathered information. The program included the following knowledge, skills, and attitude objectives which the teachers were expected to demonstrate upon its completion:

\subsubsection{Knowledge}

1) Match content knowledge on English reading instruction with a suitable reading text.

2) Explain concepts of methods of teaching English reading skills.

3) Choose appropriate classroom activities and assessment and evaluation approaches that match the selected reading text.

4) Design appropriate lesson plans to facilitate students' English reading skills development.

\subsubsection{Skills}

1) Increased capabilities to manage the learning environment when teaching English reading.

2) Increased collaborative skills.

\subsubsection{Attitude}

1) Have a positive attitude and a commitment to continuous professional development.

2) Recognize the importance of building a professional learning community. 


\subsection{Participants of the Study}

The sampling of this study was based on a voluntary basis. The study sample included 50 English teachers (48 secondary school teachers; 2 primary school teachers) enrolled in the teacher-training program entitled, "Insight into EFL Reading Instruction". Most participants were from the central part of Thailand.

\subsection{Training Program Design}

The teacher-training program was divided into three phases:

Phase I was a face-to-face two-day training initiative. Teachers were required to attend both lectures and workshops on the following four topics:

1) What to teach in a reading classroom;

2) How to teach EFL reading;

3) How to assess students reading comprehension; and

4) Designing a reading lesson (with a follow-up session).

The 50 participants were divided into 10 groups of 5 teachers each and were asked to design their own reading lesson plans.

The following is a brief summary of the topics and the contents of the training program:

Topic 1: What to teach in a reading classroom

Topic 1 included reading sub-skills which could be further studied in learning standards/indicators in the core curriculum. When preparing students for an assessment task or exam, teachers should know which reading sub-skills to cover in each reading text. Therefore, this topic supported teachers to develop their skills in designing lesson plans as well as assessment and evaluation activities.

Topic 2: How to teach reading

Topic 2 focused on improving teachers' background knowledge of the principles of reading skills development. These principles provide the foundation for the development of their teaching techniques for improving students' English reading skills. The teachers learned about different methods for teaching reading and the steps for implementing each method. The topic also offered teachers practical knowledge in how to design and implement a variety of learning activities to enhance student interest in their learning.

Topic 3: How to assess reading comprehension

Topic 3 provided teachers with insights into appropriate methods for assessing and evaluating reading skills. The methods aligned with Bloom's framework of constructivist learning behaviors and included the tools and instruments commonly used in such assessments and evaluations. As such, the topic contributed to the development of the teachers' knowledge and understanding of student assessment practices.

Topic 4: Designing a reading lesson

Topic 4 included activities whereby the teachers were required to apply the knowledge they gained during the lectures, sharing sessions with other participants, and workshops on their work practices. Specifically, the participants designed a lesson plan for a group-based learning activity in a reading classroom.

Following the completion of the training program, a follow-up session was held with the teachers to get their feedback/reflections on having applied their knowledge. For instance, they were asked about the process of applying their knowledge, if there were changes in their teaching and learning management approaches, any changes in the students, and to identify any problems and solutions, etc.

Phase II was a follow-up session reflecting Professional Learning Community (PLC) activities via LINE. LINE is a free software application for instant communications on electronic devices such as smartphones, tablet computers, and personal computers. Participants were required to return to their respective schools and to collaborate with teachers in the same department to conduct the following activities:

\subsubsection{Group Activity}

1) Each group modified the reading lesson plan they designed during Phrase I and posted the redesigned or modified version on LINE. Ten modified lesson plans were posted.

2) Each group from Phase I nominated one member to implement the modified lesson plan in their classroom and to video-record the classroom activities. They then uploaded a 5- to 10-minute video post on LINE. 


\subsubsection{Individual Activity}

Each participant chose one lesson plan posted on LINE that suited his or her interests and presented it to their colleagues (the same department) as part of a PLC activity. The colleagues were asked to help modify, adjust, and improve the lesson plan before implementing it in the classroom. Following its implementation, the participant reflected on the process and outcomes with their PLC group.

Phase III was a face-to-face one-day training session. It included a reflexive activity focusing on the implemented lesson plan followed by group discussions and concluding lectures.

\subsubsection{Validation of the Data Collection Instruments}

The instruments used for data collection in this study were tested for their validity and reliability. External experts were consulted in regard to the suitability of the contents and materials included in the training program as well as the research instruments. Four instruments were used in this study:

1) A 12-item pre-test and post-test on teaching English reading skills covered the contents of the training program.

2) An open-ended response form for participants to record emerging points following the implementation of the lesson plan and preparation of the video clip.

3) A survey including 5-point Likert-scale variable response options and an opened-ended response field to assess the teachers' satisfaction towards the training program.

4) A form for recording observational notes of teachers participating in the training program.

\subsection{Research Procedures}

\subsubsection{Study Sequence}

1) The researchers synthesized and analyzed problems that might occur when teaching English reading in the EFL classroom. This was undertaken to inform the design of the learning activities to be included in the training program.

2) The researchers studied the requirements and forms that would be proposed to the Teacher Profession Development Institute, Ministry of Education

3) The training program curriculum was adjusted and developed. The designed lessons were divided into four topics. The content of each lesson was adjusted to match the topic and the knowledge teachers were expected to demonstrate when conducting an English reading class (see section 2.4 above for the list of topics).

4) A proposal of the training program was submitted to the Teacher Profession Development Institute, Ministry of Education, for approval.

5) Following approval for the study, the dates, times, and location of the training program were set. Classes and participants were also formulated.

6) Teachers interested in attending the training program registered online through the Office of Kurupatana Institute (the Teacher Professional Development Institute: TDI).

7) The training program was successfully run as planned. Data collection was conducted without complications. An assessment of the training program was performed to evaluate its effectiveness according to its stated aims and objectives. The assessment data were analyzed using content analysis techniques and descriptive statistics including X, S.D, and T-Tests.

\section{Results}

\subsection{Effectiveness of the Training Program}

Evaluation of the training program considered its effectiveness in terms of the extent to which it achieved its objectives in the three core areas: knowledge, skills, and teachers' attitudes.

\subsubsection{Knowledge}

After comparing the participants' pre- and post-test scores, $98 \%$ of participants demonstrated a gain in knowledge and understanding of the content taught in the training program. Only $2 \%$ of participants achieved lower scores on the post-test compared to the pre-test. The average pre-test score was 5.02 compared to the average post-test of 8.74. Comparing the pre-and post-test scores revealed a statistical significance improvement $(p=0.05)$ in the participants' knowledge of teaching English reading skills in the EFL classroom. 


\subsubsection{Skills}

Participants improved their learning management skills for teaching reading. They could exhibit satisfactory performance in designing lesson plans and learning and teaching management for an English reading classroom. Participants' learning management skills were evaluated based on their participation in the training program activities. As reported, these activities included designing a lesson plan, adjusting/modifying the lesson plan with colleagues, implementing a lesson plan including taking photos and making a video recording, and producing a summary of problems and solutions. Both individual and group assignments were used in the evaluation process. Participants' video-recordings of their teaching practices were evaluated for the extent to which they implemented the designed lesson plan in their classrooms. It was found that some teachers changed their teaching practices and approach to learning management. The classroom atmosphere became more positive as students became more involved and engaged. They became more active and eager to participate in classroom activities.

\subsubsection{Teacher's Attitude}

All participants indicated an interest in participating in all training program activities. All participants reflected a positive attitude towards their professional development and participation in a professional learning community.

Observations of teachers during the three-day training activities were used in the evaluation. Specifically, they were observed for their level of active engagement in the training activities over the three days (i.e. lectures, demonstrations, workshops, test analysis, indicator analysis, designing questions for assessment and evaluation, designing lesson plans, and implementing the designed lesson plans). Regarding the follow-up activities using LINE to evaluate the teachers' application of new knowledge, this study found that the teachers were active in their work, recognized the importance of knowledge sharing, and could meet deadlines and submit all individual and group assignments. Integrating the mobile application into the training program enabled participants to work together anytime and anywhere and thus remain active in the learning community. Regarding teacher satisfaction with the training program, analysis of the opened-ended survey responses found most participants reflected a positive attitude towards the program. They reported that they knew what issues in teaching English reading skills they should improve and that they would further apply the knowledge gained from the training in their teaching practices.

\subsection{Summary of the Participants' Satisfaction towards the Training Program}

At the conclusion of the training program, the participants were asked to complete a survey to investigate their level of satisfaction with the process and outcomes. This was undertaken to assist the trainers and organizers of the program to make informed decisions about how to improve the program in the future. Table 1 shows the main results of the survey:

\subsubsection{Content and Activities}

Participants rated the content and activities of the training program as suitable and indicated that the activities were useful for them at the highest level.

\subsubsection{Speakers}

Participants rated the speakers at the highest level across all areas, especially their ability to pass on knowledge and to explain the content of the program.

\subsubsection{Atmosphere and Training Facilities and Amenities}

Participants expressed positive views about the venues and training materials.

\subsubsection{Understanding}

Participants demonstrated more knowledge of English reading teaching practices and learning management techniques at the conclusion of the training program than at its commencement. They rated their after-training knowledge at the 'high' level.

\subsubsection{Knowledge Application}

Participants showed their confidence in applying the knowledge they gained from the training program at the highest level. In terms of their perceived ability to pass on their new knowledge, they rate this at the 'high' level. 
Table 1. The participants' satisfaction towards the training

\begin{tabular}{|c|c|c|c|}
\hline Items & $\overline{\mathbf{X}}$ & S.D. & Results \\
\hline \multicolumn{4}{|l|}{ Content and activities } \\
\hline 1. The content and activities were suited the participants' needs. & 4.68 & 0.47 & Highest \\
\hline $\begin{array}{l}\text { 2. The content was suitable to develop the knowledge of the training } \\
\text { participants. }\end{array}$ & 4.68 & 0.47 & Highest \\
\hline $\begin{array}{l}\text { 3. The training activities helped participants to gain more insights into and } \\
\text { understanding of the content. }\end{array}$ & 4.68 & 0.47 & Highest \\
\hline 4. The content was useful for the participants. & 4.71 & 0.46 & Highest \\
\hline \multicolumn{4}{|l|}{ Speakers } \\
\hline 5. The speakers could clearly pass on knowledge. & 4.84 & 0.37 & Highest \\
\hline 6. The speakers could explain the content. & 4.80 & 0.40 & Highest \\
\hline 7. The connection between the topics in the training was clear. & 4.78 & 0.42 & Highest \\
\hline 8. The training content was completely explained and included. & 4.74 & 0.44 & Highest \\
\hline 9. The speakers could respond to questions during training. & 4.76 & 0.43 & Highest \\
\hline \multicolumn{4}{|l|}{ The atmosphere, training facilities, and amenities } \\
\hline 10. The training location was suitable. & 4.66 & 0.52 & Highest \\
\hline 11. Readiness and quality of audio-visual aids. & 4.62 & 0.57 & Highest \\
\hline 12. The training materials were suitable and adequate. & 4.62 & 0.60 & Highest \\
\hline 13. The food and beverages were suitable & 4.66 & 0.56 & Highest \\
\hline \multicolumn{4}{|l|}{ Understanding } \\
\hline 14. Knowledge and understanding before training. & 3.04 & 0.86 & Fair \\
\hline 15. Knowledge and understanding $\underline{\text { after training. }}$ & 4.40 & 0.53 & High \\
\hline \multicolumn{4}{|l|}{ Knowledge application } \\
\hline $\begin{array}{l}\text { 16. Be able to apply the knowledge gained from the training into work } \\
\text { practice. }\end{array}$ & 4.56 & 0.50 & Highest \\
\hline 17. Be able to disseminat/pass on the knowledge. & 4.32 & 0.51 & High \\
\hline
\end{tabular}

In addition to the survey, the participants were asked to complete the open-ended survey. Their comments and feedback were as follows:

1). Benefits gained from the training program

i. The participants now understood more about teaching English reading skills and classroom activities. They were no longer interested in implementing the activities they typically used in the reading classroom. The knowledge acquired through training, including teaching, assessment, and evaluation methods could be used and applied for further development.

i. The participants had a clearer understanding of how to design a lesson plan and set a learning activity. The following are examples of the types of new knowledge they gained on how to design a lesson plan.

ii. The participants knew more about guidelines for preparing classroom activities for teaching English reading skills.

iii. The participants knew more about guidelines for preparing activities that are consistent with the learning criteria/indicators.

iv. The participants engaged with examples from different types of reading texts that can be used within the classroom.

2). Knowledge application

i. The knowledge gained could be applied in practice. As one teacher commented; He or she needs to improve lesson plans. Before, He or she didn't pay much attention to lesson plans. He or she needs to 
create different activities so that students gain knowledge, enjoy the lesson, and are actually involved".

ii. The participants will pass along the knowledge when there is a PLC activity for teachers in the Foreign Language section.

iii. The participants will choose more interesting reading texts for students.

iv. The participants will apply the knowledge when preparing for tests and exams.

\section{Discussion and Conclusion}

The findings confirmed information from the literature that English teachers in EFL contexts need access to appropriate training to facilitate their students to meet the requirements of the national core curriculum. This is based on the evidence showing participants in the study lacked knowledge of how to refer to the national curriculum when writing their lesson plans (Ottley, 2017). Most participants employed the lesson plans commercially available from the publishers of the books they used in the classroom. These books have been authorized for use in the school because they address some of the knowledge requirements indicated in the curriculum. Nonetheless, teachers need to use them creatively by adding and integrating other authentic materials or communicative activities that will benefit the students in ways different from the traditional approach to teaching reading (Mejang, 2018). After acquiring new knowledge of what to teach and how to teach it, teachers will then have the skills to assess students' abilities in accordance with the expected learning outcomes indicated in the course objectives. Before attending the training, the participants lacked knowledge of how to set learning behavior objectives and how to assess them. After they were trained, they demonstrated their ability to set the learning objectives covering the three domains of educational activities: knowledge, skills, and attitude through their teaching demonstration (Nesari, 2014). The teachers broadened their knowledge base of how to assess students because this will impact the design of the midterm and final exams as part of the course assessment program. Teachers will also be able to adjust their teaching accordingly and to evaluate the reading materials to determine whether they are suitable for the students. Finally, the teachers will be capable to design lessons that promote the proximal development of the students' reading abilities. To conclude the training, the participants gained more knowledge about teaching reading and writing lesson plans. They are more skillful in setting learning objectives and assessing students' reading ability, and they have a positive attitude towards professional development. In conclusion, this study provides implications for further research on developing a teacher-training program using mobile technologies to promote teacher learning communities in different areas of Thailand (Reinders \& Pegrum, 2017). Using the LINE application enables teachers to work together remotely and to connect with colleagues and trainers throughout the program even though they live in different places in the country. Participants shared data, video clips, and comments to each other via the LINE application. This is also aligned with the work of (Reinders \& Pegrum) which promotes the use of mobile applications to facilitate the learning process. However, the main limitation of this study is that it gives little focus to English language skills apart from reading; namely, speaking, writing, and listening. Thus, future research should focus on effective integrated skills training programs for teachers who continue to experience difficulties teaching their students English.

\section{References}

Abdelhalim, S. M. (2017). Developing EFL students' reading comprehension and reading engagement: Effects of a proposed instructional strategy. Theory and Practice in Language Studies, 7(1), 37-48. https://doi.org/10.17507/tpls.0701.05

Block, E. L. (1992). See how they read: Comprehension monitoring of L1 and L2 readers. TESOL Quarterly, 26(2), 319-343. https://doi.org/10.2307/3587008

Bloom, B. S. (1996). Taxonomy of education objectives. Handbook 1: The cognitive domain. New York: David McKay Co Inc.

Darici, A., \& Tomlinson, B. (2017). A case study of principled materials in action. In B. Tomlinson (Ed.), SLA research and materials development for language learning (pp. 71-86). New York: Routledge.

Fan, X., \& Li, L. (2020). Teacher cognition of creativity in primary EFL classrooms. In L. Li (Ed.), Thinking skills and creativity in second language education: case studies from international perspectives (pp. 195-215). New York: Routledge. https://doi.org/10.4324/9781315098920-10

Feeney, T., \& Gajaseni, C. (2020). Effectiveness of reading short stories to develop intercultural communicative competence among Thai students at an International school. LEARN Journal: Language Education and Acquisition Research Network Journal, 13(2), 126-141.

Garcia, A. (2014). Teachers' agency and connected learning. In A. Garcia (Ed.), Teaching in the connected learning classroom (pp. 6-9). Irvine, CA: Digital Media and Learning Research Hub. 
Gordon, J. (2015). Teaching English in secondary schools. United Kingdom: Sage. https://doi.org/10.4135/9781473918443

Ishihara, N., \& Paller, L., D. (2017). Research-informed materials for teaching pragmatics: The case of agreement and disagreement in English. In B. Tomlinson (Ed.), SLA Research and Materials Development for Language Learning (pp. 87-100). New York: Routledge.

Krathwohl, D. R., Bloom, B. S., \& Bertram, B. M. (1973). Taxonomy of educational objectives, the classification of educational goals. Handbook II: Affective Domain. New York: David McKay Co., Inc.

Mejang, A. (2004). The development of an English reading strategy instruction model based on collaborative learning principles for enhancing reading learning outcomes of university students. Unpublished doctoral dissertation. Chulalongkorn University, Thailand.

Mejang, A. (2018). The development of a web-based training package on integrated-skills approach to English language teaching for secondary school English teachers. Journal of Education Naresuan University, 19(4), 276-292. Retrieved from https://so06.tci-thaijo.org/index.php/edujournal_nu/article/view/93821/85790

Naofaie, H. A. (2020). Teaching theoretical linguistics through thinking skills pedagogies. In L. Li (Ed.), Thinking skills and creativity in second language education: case studies from international perspectives ( $\mathrm{p}$. 69). New York: Routledge.

Nation, I. S. P., \& Macalister, J. (2021). Teaching ESL/EFL Reading and Writing (2nd ed.): Routledge. https://doi.org/10.4324/9781003002765

Nesari, J. A. (2014). The important role of lesson plan on educational achievement of Iranian EFL teachers' attitudes. International Journal of Foreign Language Teaching \& Research, 2(5), 28-33.

Ottley, K. (2017). Why one-size-fits-all Is not fit for purposes: The problem with mass-produced teaching materials, and how one might creatively and sensitively confront this problem. In B. Tomlinson (Ed.), SLA Research and Materials Development for Language Learning (pp. 268-279). New York: Routledge.

Pan, L. (2009). Sub-skills approach and extensive approach to reading in TEFL. Journal of Cambridge Studies, $4(3), 112-120$.

Petchinalert, S., \& Aksornjarung, P. (2017). English reading strategies and proficiency: A case study of Thai EFL teachers. Journal of Liberal Arts, Prince of Songkla University, Hat Yai Campus, 9(2), 117-139.

Pustika, R., \& Wiedarti, P. (2019). The implementation of reading instruction in the EFL classroom. ETERNAL (English Teaching Learning and Research Journal), 5(1), https://doi.org/10.24252/Eternal.V51.2019.A7

Reinders, H., \& Pegrum, M. (2017). Supporting language learning on the move: An evaluative framework for mobile language learning resources. In B. Tomlinson (Ed.), SLA Research and Materials Development for Language Learning (pp. 219-230). New York: Routledge.

Sawangsamutchai, Y., \& Rattanavich, S. (2016). A comparison of seventh grade Thai students' reading comprehension and motivation to read English through applied instruction based on the Genre-based approach and the teacher's manual. English Language Teaching, 9(4), 54-63. https://doi.org/10.5539/elt.v9n4p54

Spangler, D., \& Mazzante, M. J. (2015). Using reading to teach a world language: strategies and activities. New York: Routledge. https://doi.org/10.4324/9781315722757

Sukchotrat, M. (2012). Reading from Lower to Higher Levels: Learning to Teach. Bangkok: Nami Book Publishing (in Thai).

The National Institute of Educational Testing Service Public Organization. (2020). Summary of Ordinary National Educational Test (O-NET) result of Academic year 2019. Retrieved from https://www.newonetresult.niets.or.th/AnnouncementWeb/PDF/SummaryONETM3_2562.pdf

Urquhart, A. H., \& Weir, C. J. (1998). Reading in a second language: Process, product and practice. London and New York: Longman.

\section{Copyrights}

Copyright for this article is retained by the author(s), with first publication rights granted to the journal.

This is an open-access article distributed under the terms and conditions of the Creative Commons Attribution license (http://creativecommons.org/licenses/by/4.0/). 